\title{
In memoriam of Konrad Heusler
}

\author{
Gyözö G. Láng ${ }^{1}$
}

Received: 17 November 2015 / Accepted: 18 November 2015 /Published online: 2 December 2015

(C) Springer-Verlag Berlin Heidelberg 2015

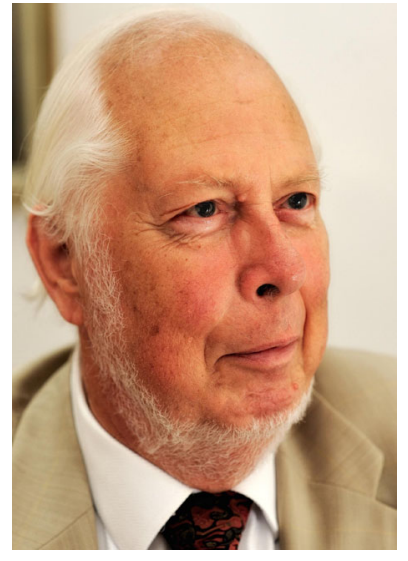

20 December 2015 marked the first anniversary of the death of Professor Konrad E. Heusler, a pivotal figure in electrochemistry and a man widely regarded as a leading expert in corrosion science and surface chemistry of metals. Professor Heusler passed away after a long illness at the age of 83 years. In remembering him, we think of all that he represented and accomplished during his life and career.

Professor Heusler was 65 years old when he retired in 1996 after a distinguished career that spanned more than 40 years. However, he remained active in research long after his retirement and continued to work on scientific problems practically until his death. During his career, he authored over 180

Gyözö G. Láng

langgyg@chem.elte.hu

1 Institute of Chemistry, Department of Physical Chemistry \& Laboratory of Electrochemistry and Electroanalytical Chemistry, Eötvös Loránd University, H-1117 Budapest, Pázmány P. s. 1/A, Hungary publications in the form of books, book chapters, patents, and papers in prestigious journals and conference proceedings. To many of us, we learned from Professor Heusler through his passionate and tireless efforts as a researcher, mentor, and teacher. He inspired a generation of researchers who are at work today in Germany and around the world.

His interest in metals and physical chemistry came from his family. The Heusler alloys, so named in honor of their discoverer, are a very important family of intermetallic compounds. At the beginning of the twentieth century, this special group of alloys was discovered by Friedrich (Fritz) Heusler (18661947), the grandfather of Professor Konrad E. Heusler. These alloys are remarkable for the fact that, in certain proportions, they are ferromagnetic, although the component metals are not ferromagnetic. His father, Otto Heusler (1901-1996), was an eminent Physicist who explored, among other things, the fcc structure of the $\mathrm{Cu}_{2} \mathrm{MnAl}$ compound.

Konrad Heusler was born in 1931 in Heidelberg, later, he moved to Dillenburg/Hessen. From 1951 until 1955, he studied chemistry at the University of Göttingen. He prepared his diploma thesis as well as his PhD thesis at the Max-PlanckInstitute for Physical Chemistry in Göttingen under the supervision of Professor Karl Friedrich Bonhoffer. The topic of his diploma work was the study of the passivity of iron in alkaline solutions. After his diploma, he joined Bonhoffer's group at the Max-Planck-Institute, and it was here that he began his illustrious career in research. The research activities of this laboratory focused extensively on questions of electrochemical kinetics. Konrad E. Heusler was studying the kinetics of the active dissolution of iron and with a thesis on this subject; he was awarded his $\mathrm{PhD}$ in 1957.

In the second half of the 1950s, the investigation of the kinetics and mechanisms of metallic electrodissolution was advanced significantly by Bonhoeffer and Heusler's proposal that univalent iron surfaces were involved in anodic dissolution 
of iron during corrosion. The rate determining charge transfer controlled step was assumed to take place at active surface sites. Subsequently, Konrad Heusler proposed an $\mathrm{OH}^{-}$-accelerated mechanism of iron electrodissolution, i.e., the so-called "catalytic" iron dissolution mechanism, which now bears his name ("Heusler mechanism of iron dissolution").

After the death of Professor Bonhoeffer, he moved to the Max Planck Institute for Iron Research in Stuttgart where he established a new electrochemistry research group. In 19571959, he completed a visiting research fellowship at Oak Ridge National Laboratory in Tennessee (his host was G.H. Cartledge). Konrad Heusler made his Habilitation in 1966 at TU Stuttgart (his mentor was the renowned Th. Foerster).

In 1971, he was appointed as a professor at the Clausthal University of Technology (Technische Universität Clausthal, Clausthal-Zellerfeld, Germany) where he founded the Department of Corrosion and Corrosion Protection. He chaired the Department from 1971 until his retirement in 1996. Not only was he to continue his first class research and establish a new research school, but in keeping with his senior position at the university he became inevitably more involved with science administration. Konrad Heusler was the regional representative for Germany in the International Society of Electrochemistry (ISE) for the years 1975-1985, and chairman of the ISE Division on Electrochemical Kinetics and Electroanalytical Chemistry from 1978 until 1984. He served as Chairman of the Corrosion, Electrodeposition and Surface Treatment Division of ISE (1991-97), as a member of the IUPAC Committee of Electrochemistry (1977-1985), and as Chairman of this committee for 2 years (1982-1983). He also organized several international meetings, including the 7th International Symposium on Passivity of Metals and Semiconductors which was held in Clausthal-Zellerfeld. As symposium chairman Professor Heusler was able to update the history of passivity once more and provide additional valuable references to its history. It may be noted that, as a student of Bonhoeffer through whose vision, the first symposium was held Konrad Heusler attended every symposium.

In his research at TU Clausthal Konrad Heusler soon developed his own style and attracted increasing numbers of students, scholars, and visiting scientists (including several Humboldt research fellows) from all over the world to Clausthal.
He initiated several new areas of research, including, e.g., the electrochemical and corrosion properties of metallic glasses, the electrochemical kinetics of the formation and dissolution of oxide layers, the measurement and analysis of electrochemical noise, the energetics of electrically polarized solid/liquid interfaces, the corrosion of metals and alloys in non-aqueous media, but he also continued his research on classical electrode kinetics. The experimental results obtained on iron single crystal surfaces led to a first "quasi-atomistic approach" of the iron dissolution reaction in the active range postulated by Allgaier and Heusler. The "active sites" in the catalytic mechanism were correlated to kink sites, and it was shown that their surface concentration follows a surface relaxation process depending on the electrode potential.

All these findings marked the start of a new era in surface electrochemistry and represented the start of modern surface electrochemistry.

At the 7th International Symposium on Passivity of Metals and Semiconductors Heusler pointed out "Practically, complete equilibrium is never attained during the lifetime of a technical device. At room temperature, reaction rates at solid interphases and mobilities in the solid bulk are much too slow." As M.B. Ives noted "This is an important consideration in relating the results of carefully controlled laboratory experiments to the behaviour of the same materials in the field".

Konrad Heusler was also an ingenious experimenter and instrument maker who insisted on the highest possible accuracy when taking measurements. Among his inventions were a low-noise potentiostat, a ring-disc electrode with a transparent ring, a Kösters-interferometer for the measurement of interfacial stress changes, an ellipso-refractometer and a system based on the electrochemical quartz crystal microbalance for measuring the internal stress in thin oxide layers.

In recognition of his achievements, in 1991, he was awarded the prestigious T.P. Hoar Prize.

Konrad Heusler made a huge difference to a lot of people in his lifetime. Many young scientists were inspired by his passion for electrochemistry and surface science always delivered in very clear and simple terms. He will remain in the memory of all who knew him, as a role model of a successful researcher and open-minded teacher. We deeply miss Professor Heusler, this outstanding scientist, but are grateful that he left behind such a rich legacy. 